\title{
Posted price model based on GRS and its optimization for improving grid resource sharing efficiency
}

\author{
Mingbiao Li • Naixue Xiong • Bo Yang • Zhonghua Li • \\ Jong Hyuk Park • Changhoon Lee
}

Published online: 3 August 2013

(c) The Author(s) 2013. This article is published with open access at Springerlink.com

\begin{abstract}
In the existing economy based models of grid resource allocation and management, just as commodity market model and posted price model, sharing resource is based on negotiating about the usage duration or time, the usage fee, QoS (Quality of Service) and some other items between the owner or his broker and the consumer of grid resource. That will cost so much time for a great deal of grid users
\end{abstract}

This paper organically combines and extends three ourselves conference papers which appear in [25, 26], and [27], respectively.

\section{Li (ه)}

Department of Information, Wenzhou University,

325035 Zhejiang, China

e-mail: jsjlmb@wzu.edu.cn

\section{N. Xiong $(\varangle)$}

School of Computer Science, Colorado Technical University,

Colorado Springs, CO 80907, USA

e-mail: nxiong@coloradotech.edu

B. Yang $\cdot$ Z. Li

School of Information Technology, Jiangxi University of Finance

\& Economics, Jiangxi, China

B. Yang

e-mail: jxncyangbo2002@163.com

Z. Li

e-mail: chinalee@jxufe.edu.cn

J.H. Park

Department of Computer Science and Engineering, Seoul

National University of Science and Technology, Seoul,

South Korea

e-mail: jhpark1@ snut.ac.kr

\section{Lee}

Department of Computer Science and Engineering, Seoul

National University of Science and Technology, Seoul, South

Korea

e-mail: changhoonlee08@gmail.com no matter whether they are grid resource owners or grid resource consumers, which reduced the sharing efficiency in the grid environment and some time is even unacceptable. In this paper, for solving the problem as described above, we present a scheme which is combined by 3 aspects: one is GRS (Grid Resource Supermarket), the second one is posted price model based on GRS, the third one is optimization based on MOGAP (Multi-Objects Generalized Assignment Problem). In the end, three examples are given to show the feasibility of our scheme.

Keywords Grid resource allocation - Sharing efficiency · GRS · MOGAP · Optimization

\section{Introduction}

Grid resource allocation and management is very complicated and difficult problem because the resources are distributed, heterogeneous in nature, owned by different individuals or organizations each having their own resource management policies and different access-and-cost models. Thus, some resource allocation and management models based on market, or economic models in the grid have been proposed such as commodity market, posted price, tenders and auctions, negotiation price model, contract agreement, model of auctioning, employing exchange model of bid [13]. Generally, based on these models, resource consumers make use of GRBs (Grid Resource Broker) to submit applications of the resource consumption. GRBs meet the requirements of these resource consumers via grid middleware services. It is obvious that the process of the sharing will cost much time at negotiating about the usage duration or time, the usage fee, QoS and some other items about sharing access. On the other hand, it is also clear that these models are 
only beneficial to the grid consumer, who can finish their work at the lower cost.

In this paper, we try to solve the efficiency bottleneck of grid resource sharing, which is combined by 3 aspects: one is GRS, the second one is posted price model based on GRS, the third one is optimization based on MOGAP. We also try to be on behalf of GRM (Grid Resource Manager) and propose the idea of GRS to meet the service of grid resource sharing. Supermarket is welcomed by people and fits the habit of people's consumption. Constructing GRS by GRS user agent and GRS resource agent, serving grid consumer via GRS user agent, organizing the grid resource from their owner and negotiating about the time, the price and the QoS of resource sharing, we get a new idea of GRAM (Grid resource allocation and management) based on economic model. One important thing is that all the negotiating interaction between the resource provider and the GRS resource agent is finished in background instead of foreground before the resource sharing. After construction of GRS, the grid resources consumer shares the resource just as in the posted price model. Of course, the GRS is always changing because grid is dynamic. Furthermore, GRS managers can profit from price difference between the cost and sale price of the GRS resource. Generalized Assignment Problem (GAP) is used to allot the resource in GRS to optimize the allocation of resource.

The paper is organized as follows. In Sect. 2, the related work are presented. Section 3 introduces the posted price model. Section 4 presents the idea of GRS and its construction. In Sect. 5, the GRS-based posted price model is defined. Section 6 discusses the optimization of allocation of resource. There are some examples in Sect. 7. Finally, conclusions and future work are outlined in the last Sect. 8.

\section{Related works}

Our work is based on GRS built in virtual organization (VO). Foster clarifies the concept about VO in [4]. VO is a set of individuals and institutions defined by uniform sharing rules.

Classifying based on the economic model, our work falls into the category of posted price model. Posted price model is similarly to the commodity market [5], except that special offers are advertised for notifying consumers discounted prices $[6,7]$. One recent work about the commodity market is presented by Gunther Stuer etc., where in order to find price equilibria in commodity market, some refinements of Smale's method application are proposed [8]. Some other related economic models are bargaining, tendering/contractnet, auction, bid-based, bartering, monopoly and oligopoly, and other various forms.

In bargaining, providers and consumers negotiate each other. Providers commonly want to get higher prices but consumers want to get lower prices. This negotiation continues until both providers and consumers all agree a same price which is acceptable to them. When the price is difficult to define, bargaining is a well economic model to achieve a acceptable price [9]. Tendering /contract-net allows a customer announces requirements to potential producers for looking for the desirable provider [10]. Auction allows consumers to submit bids through an auctioneer until a single clearing price appears, this price is higher than the price other customers can accept [11]. A typical bidbased is the resources assigned are in direct proportion to the bids of the consumers [12]. Bartering supports sharing each others' resources between providers and consumers, if consumers are also providers and thus both contribute and use resources [13]. Monopoly/oligopoly is non-competitive. There are only a single or a number of providers determines the price [14].

In the commodity market model, resource providers specify their service price and charge users according the amount of resource they consume. A provider uses a brokering system where each request is distributed until the accumulated brokerage cost is limited by the budget of the user [5]. The pricing policy can be derived from various parameters and can be flat or variable depending on the resource supply and demand. In general, services are priced in such a way that supply and demand equilibrium is maintained. Logic structure of commodity model is just shown in Fig. 1.

Some in-depth works on posted price model are presented in [15-17]. Anastasiadi etc. present three routing algorithms which are related with expected completion time and required network bandwidth [28]. Based on it, they investigate the load balancing economy occasions in which providers can advertise prices and transaction requests at a bulletin board [15]. Ferguson etc. investigate the load balancing economy occasions in which First-price and Dutch auctions enable each provider to host its independent auction, and enable users to decide which auction they should participate according to last prices advertised in bulletin boards [16]. In [17], when advertising resource request and prices on a bulletin board, currency flow is used to restrict resource usage in order to control potential intrusion attacks and minimize the damages.

\section{Posted price model}

Posted price model is related on the commodity market model [1-3]. Two key players driving the grid marketplace are GSPs (Grid Service Providers) and GRBs (Grid Resource Brokers). The posted price model is similar to the commodity market model except that it advertises special offers in order to attract (new) consumers to establish market share or motivate users to consider using cheaper slots. 


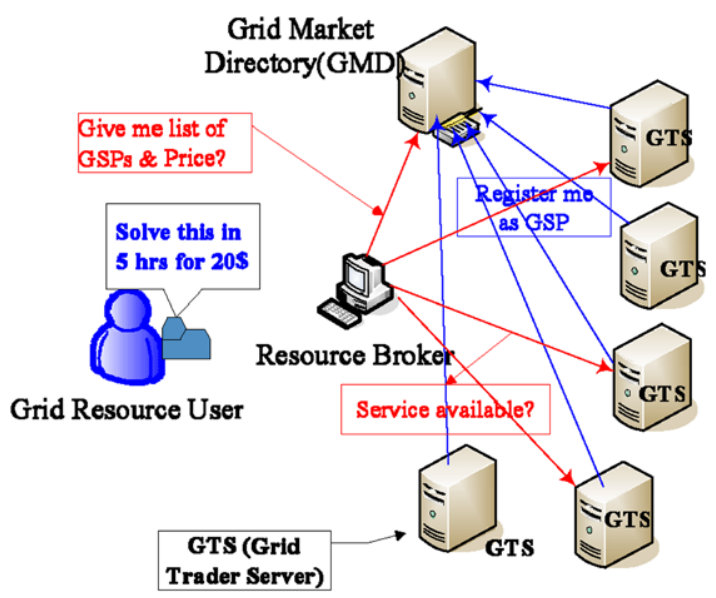

Fig. 1 Interaction between GSPs and users in a commodity market Grid for resource trading

Logic structure of posted price model is given in Fig. 2. In this case, brokers need not negotiate directly with GSPs for flat fee, usage duration or time, QoS etc., but use posted prices as they are generally cheaper compared to regular prices. The posted-price offers will have usage conditions, but they might be attractive for some users.

In Figs. 1, 2, consumers interact with their own brokers for managing and scheduling their computations on the grid. The GSPs make their resource grid enabled by running software systems along with GTS (Grid Trading Services), which enables resource trading and execution of consumer requests directly through GRBs. The interaction between GRBs and GSPs during resource trading is mediated through a GMD (Grid Market Directory). They use various economy models or interaction protocol for deciding service access price. As there are much grid resource user and a great deal of resources in grid environment even in a VO (Virtual Organization), time and efficiency will be their problems.

Some researchers have focused on the job scheduling part of a grid management infrastructure [18]. They either proposed a framework for price-based resource allocation and resources pricing algorithm to achieve maximized utilization of grid resources [19], or formalized the resource allocation problem for Service Level Agreement (SLA)constrained grid applications [20].

\section{Constructing GRS based on multi-agents}

The GRS is a virtual, logic entity. It consists of information of a great deal of GSPs (Grid Service providers) and grid resources including traditional resources: computer, network, storage system, and highly generic sense resources that means any capability that may be shared and exploited in a networked environment: database, data transfer, simulation [21]. Obviously, the principle of constructing GRS is to

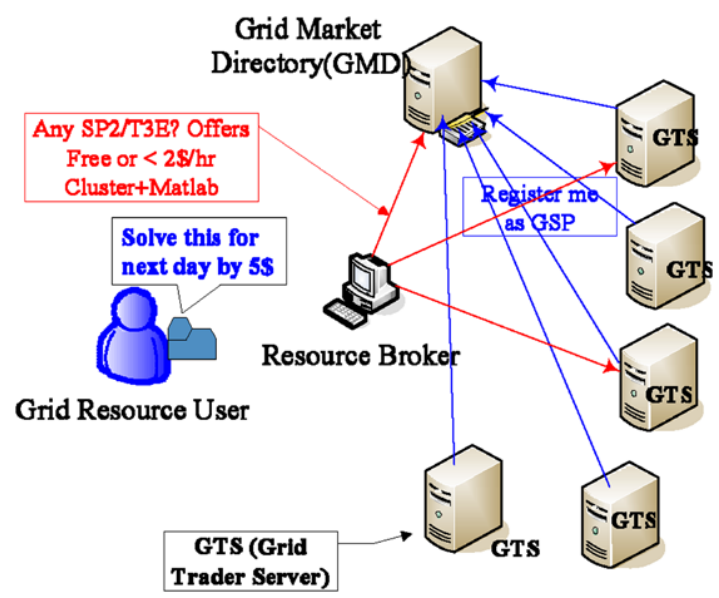

Fig. 2 Posted price model and resource trading in a computational market environment

serve the grid users whether they are grid resource providers or consumers, and make the managers of GRS get more profits. In other words, GRS gets the permission of grid resource from the providers or owners of resource in lower price and sell it at higher price to the grid consumers. GRS resource agent and GRS user agent play an important role in GRS management. The model of constructing GRS is as Fig. 3. GRS resource agents take charge of collecting the information of grid resource that can be shared by any others, negotiating about the price and the other items with the resource provider. GRS user agents take charge of responding the grid consumers and leading to the consumers sharing the resources in two modes that we will introduce at the next paragraph.

The grid consumer GRS is built in a VO (Virtual Organization) [22]. Of course, there maybe server GRS in some VO. GRS is a dynamic virtual entity while the resource in it can login or logout dynamic.

For ease of understanding, let's firstly introduce the concept about VO (Virtual Organization). In grid environment, sharing resource coordinately and solving problems in $\mathrm{VO}$ mode are two key functions which should be provided. VO is a set of individuals and institutions defined by uniform sharing rules. This sharing is, necessarily, highly controlled, with resource providers and consumers defining clearly and carefully just what is shared, who is allowed to share, and the conditions under which sharing occurs [4]. Most solving and brokering strategies in grid environment are closely related with this sharing.

The profits of GRS is depended on the policy of the resources that how much to buy in and how much to sell out. Therefore, the resource value in GRS needs to be defined as a function of many parameters as follows: Resource Value $=$ Function (Resource strength, Cost of physical resources, Service overhead, Demand, Value perceived by the user, Preferences). It is also obviously that the resource value can vary after a period of time. 
Fig. 3 Logic Structure of GRS (Grid Resource Supermarket)

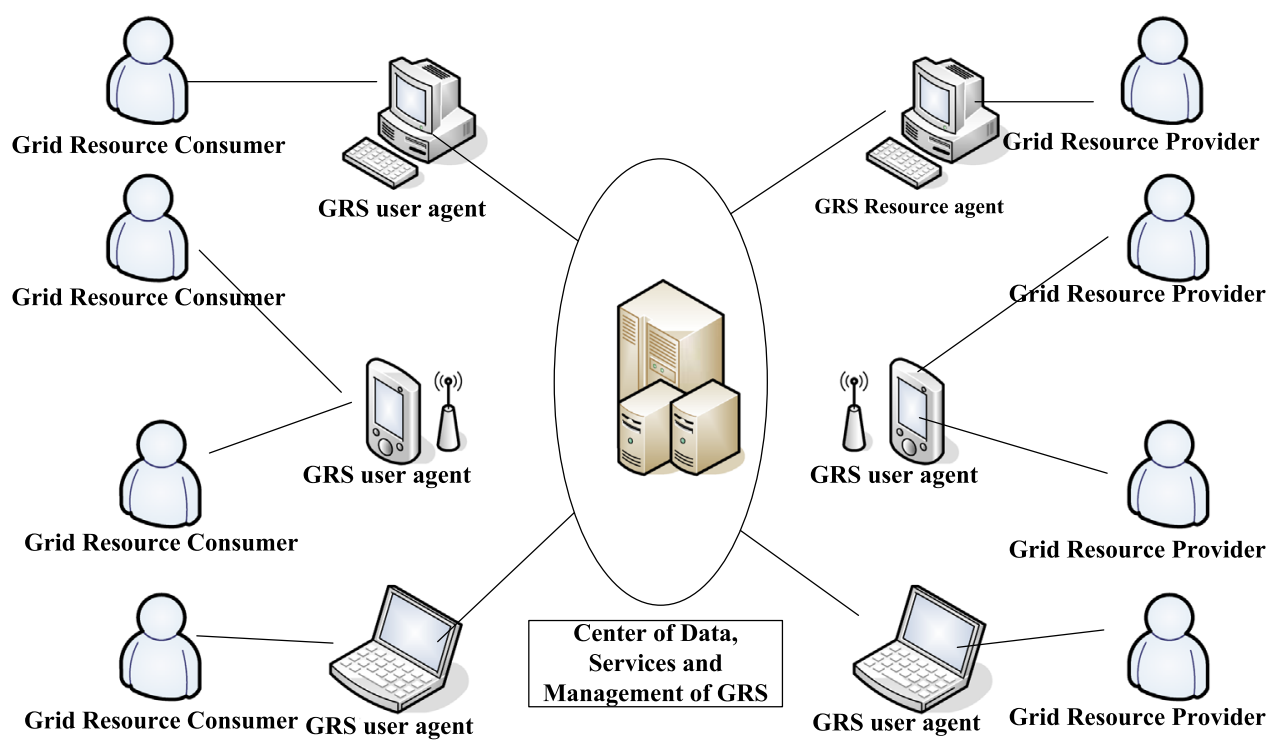

The pricing strategy of GRS is a key problem for their manager. It includes two parts in this paper. One is posted price based GRS model. The other is grid resource optimization based Assignment Problem (AP).

\section{Posted price model based on GRS}

In the posted price model based on GRS, price is negotiated back the stage by GRS resource agent and grid resource provider. Of course, it is different from the model of posted price which the price is negotiated on the stage.

This is a simplified resource mode based on economy. In this model, grid resource consumers share the GRS resource at posted price. It would not spend time to negotiating about the time, the price, the QoS etc. each other. The manager of GRS gains the profits by serving the grid resource provider and grid resource consumer. The grid resource consumers share the resource at posted price according to their plans and pocketbooks. The grid resource provider gains his income for his resource being shared. The description of this mode is as follows. We might as well suppose that our GRS has $\mathrm{n}$ pieces of resources, each resource has his ID, resource name, bank account of owner, access time for sharing, resource amount, price etc., which can be formalized as $G R S-R_{i}=\left(R_{i}-I D, R_{i}\right.$-name, $R_{i}$-account, time, amount, $\left.R_{i \text {-price-in }}, \ldots, R_{i}-I P\right) i=1,2, \ldots, n$. We also might as well suppose that $G R S-R i$ is shared by some grid consumers. The homologous item's formula is Sell- $R_{i}=\left(R_{i}-I D, R_{i}\right.$-name, $R_{i}$-account, time, amount, $\left.R_{i \text {-price-out }}, \ldots, R_{i}-I P\right) \quad i=1,2$, $\ldots, n$. Therefore, the manager of GRS gains the profits according to the followings:

profits $=\sum_{i=1}^{n}\left(\left(R_{i-\text { price-in }}\right)-\left(R_{\text {i-price-out }}\right)\right)$
In general, $R_{i-p r i c e-i n}$ is bigger than $R_{i-p r i c e-o u t}$, thus the manager of GRS can get profits.

There are obvious differences between conventional posted price model and GRS-based posted price model. The main difference is that, all the details about resource sharing such as cost fee, usage duration or time, QoS and other items in our approach are negotiated about while the GRS is constructed. That means a foreground task is changed into background task, and an instant task is changed into preparatory one. Time for negotiating is not necessary any more. It is just the advantage of our approach.

\section{Optimization based on GAP}

The scheme includes two parts. One is the posted price model based on GRS. The other is grid resource optimization based on GAP (Generalized Assignment Problem) in order to maximize the profits for the GRS manager, which will be presented in this section.

The GRS-based posted price model is fit to the sporadic grid consumers. For the group consumers, a optimized approach is proposed as follows.

Generally, assignment problem can be defined as: There are $n$ persons and $n$ pieces of jobs. Any person can be assigned to perform any job, incurring profits that may vary depending on the person-job assignment. If person $j$ finished the job $i$ by efficiency $e_{i j}$, it is required to perform all tasks by assigning exactly one person to each job in such a way that the total profits of the assignment is maximized. Furthermore, if there are $m$ persons and $n$ pieces of jobs, and $m \geq n$, which means some job can be done by more than one person. The problem is changed into GAP (General Assignment Problem) [22, 23]. Obviously, the two cases are single 
object and not adapt to allocation of GRS. Thus, for making it fit to our problems, we need to reconstruct GAP and change it into multi-object GAP. The problems are merely divided into the following two cases [24].

Case 1 There are $n$ pieces of resources and $m$ jobs $(m \geq n)$. It is required to perform all jobs by assigning one piece of resource to $b_{j}\left(b_{j} \geq 1\right.$ one or more than one) job(s) in such a way that the total profits of the assignment is maximized. Here $b_{j}$ is an unknown number, and

$$
\sum_{j=1}^{n} b_{j}
$$

We might as well suppose that allocation should think about $p$ factor such as router, bandwidth, price, etc. Assume factor $k(k=1,2, \ldots, p)$ that resource $j$ arranged to job $i$ can make GRS economy efficiency $e_{i j}(i=1,2, \ldots, m ; j=$ $1,2, \ldots, n)$, the problem is how to allocate the assignment and make the manager of GRS get the maximum profits.

\section{Model 1}

$$
\max ^{\prime} \text { profit }_{k}=\sum_{i=1}^{m} \sum_{j=1}^{n} e_{i j}^{k} x_{i j}
$$

$(k=1,2, \ldots, p)$

s.t.

$\sum_{j=1}^{n} x_{i j}=1 \quad(i=1, \ldots, m)$

$\sum_{j=1}^{n} \sum_{i=1}^{m} x_{i j}=m$

$x_{i j} \in\{0,1\} \quad(i=1,2, \ldots, m ; j=1,2, \ldots, n)$

Case 2 There are $n$ pieces of resources and $\mathrm{m}$ jobs $(m \leq n)$. It is required to perform all jobs by assigning $a_{i}$ ( $a_{i} \geq 1$ one or more than one) piece of resource(s) to one job in such a way that the total profits of the assignment is maximized. Here $a_{i}$ is an unknown number, and

$\sum_{i=1}^{n} a_{i}$

We might as well suppose that allocation should think about $\mathrm{p}$ factor such as router, bandwidth, price, etc.

Model 2

$$
\max ^{\prime} \text { profit }_{k}=\sum_{i=1}^{m} \sum_{j=1}^{n} e_{i j}^{k} x_{i j}
$$

$(k=1,2, \ldots, p)$

s.t.

$\sum_{i=1}^{m} x_{i j}=1 \quad(j=1, \ldots, n)$

$\sum_{i=1}^{m} \sum_{j=1}^{n} x_{i j}=m$

$x_{i j} \in\{0,1\} \quad(i=1,2, \ldots, m ; j=1,2, \ldots, n)$

Assume factor $k(k=1,2, \ldots, p)$ that resource $j$ arranged to job $i$ can make GRS economy efficiency $e_{i j}$ ( $i=$ $1,2, \ldots, m ; j=1,2, \ldots, n)$, the problem is how to allocate the assignment and make the GRS manager get the maximum profits.

\section{Performance evaluation}

Model $1 \&$ Model 2 is a general model of allocation of GRS. The solution of these two models has been finished. According to the procedure of multi-object GAP1\& multi-object GAP2 [23, 24], we can make a program to simulate test with $\mathrm{C}++$. We give three examples to show the feasibility of our scheme.

\subsection{The first example}

Suppose

$M \_1=\left(\begin{array}{cccc}4 & 9 & 6 & 4 \\ 3 & 8 & 5 & 4 \\ 3 & 11 & 6 & 8\end{array}\right)$

$M \_2=\left(\begin{array}{llll}3 & 5 & 4 & 7 \\ 5 & 7 & 8 & 9 \\ 5 & 6 & 7 & 8\end{array}\right)$

$M \_3=\left(\begin{array}{llll}0.64 & 0.79 & 0.84 & 0.77 \\ 0.76 & 0.81 & 0.84 & 0.85 \\ 0.70 & 0.69 & 0.78 & 0.68\end{array}\right)$

as a small scale case just $n=4$ and $m=3$, and matrix $M \_1, M \_2, M \_3$ is such as matrix of time if each resource would allocate each job, matrix of price if each resource would allocate each job and matrix of efficiency if each resource would allocate each job. After calculating we can get the following:

$R=\left(\begin{array}{llll}0.29 & 0.43 & 0.58 & 0.73 \\ 0.63 & 0.62 & 0.84 & 0.96 \\ 0.54 & 0.25 & 0.65 & 0.47\end{array}\right)$ 


$$
\begin{aligned}
A & =\left(\begin{array}{llllll}
0.29 & 0.43 & 0.58 & 0.73 & 0 & 0 \\
0.63 & 0.62 & 0.84 & 0.96 & 0 & 0 \\
0.54 & 0.25 & 0.65 & 0.47 & 0 & 0 \\
0.29 & 0.43 & 0.58 & 0.73 & 0 & 0 \\
0.63 & 0.62 & 0.84 & 0.96 & 0 & 0 \\
0.54 & 0.25 & 0.65 & 0.47 & 0 & 0
\end{array}\right) \\
A & =\left(\begin{array}{llllll}
0.67 & 0.53 & 0.38 & 0.23 & 0.96 & 0.96 \\
0.33 & 0.34 & 0.12 & 0 & 0.96 & 0.96 \\
0.42 & 0.71 & 0.31 & 0.49 & 0.96 & 0.96 \\
0.67 & 0.53 & 0.38 & 0.23 & 0.96 & 0.96 \\
0.33 & 0.34 & 0.12 & 0.96 & 0.96 & 0.96 \\
0.42 & 0.71 & 0.31 & 0.49 & 0.96 & 0.96
\end{array}\right)
\end{aligned}
$$

Matrix $R$ is called a compositive matrix about fuzzy relationship. We can also calculate the expand benefit matrix $A$.

According to the Hungary algorithm [23], we can also calculate the matrix $A$.

Combining the fuzzy theory with Hungary algorithm which is applied to solve conventional assignment problem, the last allocation of resource is calculated as the following matrix $X$.

$$
X=\left(X_{i j}\right)_{6 \times 6}=\left(\begin{array}{cccccc}
0 & 1 & 0 & 0 & 0 & 0 \\
0 & 0 & 1 & 0 & 0 & 0 \\
1 & 0 & 0 & 0 & 0 & 0 \\
0 & 0 & 0 & 0 & 1 & 0 \\
0 & 0 & 0 & 1 & 0 & 0 \\
0 & 0 & 0 & 0 & 0 & 1
\end{array}\right)
$$

According to the previous four column of matrix $X$, $x_{31}=1, x_{12}=1, x_{23}=1 x_{54}=1$, it is easy to decide the allocation of the resources. That is the first resource to the third job, the second resource to the first job but the third and fourth resources together to the third job. That is the optimization of this allocation.

\subsection{The second example}

\section{Suppose}

$$
\begin{aligned}
G_{1} & =\left(\begin{array}{lll}
11 & 8 & 8 \\
3 & 6 & 7 \\
6 & 9 & 4 \\
7 & 9 & 7
\end{array}\right) \\
G_{2} & =\left(\begin{array}{lll}
0.70 & 0.78 & 0.64 \\
0.79 & 0.79 & 0.69 \\
0.77 & 0.85 & 0.82 \\
0.67 & 0.73 & 0.68
\end{array}\right) \\
G_{3} & =\left(\begin{array}{lll}
0.78 & 0.88 & 0.68 \\
0.90 & 0.92 & 0.78 \\
0.88 & 0.89 & 0.91 \\
0.76 & 0.89 & 0.67
\end{array}\right)
\end{aligned}
$$

as a small scale case just $n=4$ and $m=3$, and matrix $G_{1}$, $G_{2}, G_{3}$ is such as matrix of time if each resource would allocate each job, matrix of price if each resource would allocate each job and matrix of efficiency if each resource would allocate each job. After calculating we can get matrix $A$ :

$$
A=\left(\begin{array}{lll}
0.26 & 0.63 & 0.14 \\
0.88 & 0.78 & 0.41 \\
0.69 & 0.71 & 0.90 \\
0.33 & 0.52 & 0.23
\end{array}\right)
$$

Combining the fuzzy theory with Hungary algorithm which is applied to solve conventional assignment problem, the last allocation of resource is calculated as the following matrix $X$.

$$
X=\left(\begin{array}{llllll}
0 & 1 & 0 & 0 & 0 & 0 \\
1 & 0 & 0 & 0 & 0 & 0 \\
0 & 0 & 1 & 0 & 0 & 0 \\
0 & 0 & 0 & 0 & 1 & 0 \\
0 & 0 & 0 & 1 & 0 & 0 \\
0 & 0 & 0 & 0 & 0 & 1
\end{array}\right)
$$

According to the previous four row of matrix $X$, it is easy to decide the allocation that makes the profits reach its maximum. The assignment is:

The second resource to the first job;

The third resource to the third job;

The first and the fourth resource are arranged to the second job.

\subsection{The third example}

Assume profit matrix

$P=\left(\begin{array}{cccc}3 & 6 & 4 & 0 \\ 8 & 10 & 15 & 8 \\ 13 & 8 & 7 & 2 \\ 2 & 7 & 12 & 4\end{array}\right)$

Max profits $=\sum_{i} \sum_{j} P_{i j} X_{i j}$

According to above $X$ value, Formula (2) can be changed to (3)

Min temp $=\sum_{i} \sum_{j} c_{i j} X_{i j}$

Coefficient matrix $C=\left(\begin{array}{cccc}14 & 11 & 13 & 17 \\ 9 & 7 & 2 & 9 \\ 4 & 9 & 10 & 15 \\ 15 & 10 & 5 & 13\end{array}\right)$

The Hungarian algorithm can mainly be described as the follows:

This algorithm depends on two features of the assignment problem: 
- Each resource must be assigned to one and only one job and vice versa.

- In the coefficient matrix $C$, a constant can be added or subtracted from all $C_{i j}$ in a row or all $C_{i j}$ in a column without having any effect on the set of optimal assignment. There are three steps in the Hungarian algorithm:

Step 1: Find the opportunity coefficient matrix.

Step 2: Test for an optimal assignment. If an optimal assignment can be made, make it and stop.

Step 3: Revise the opportunity coefficient matrix and return to step 2.

Let us apply Hungarian algorithm to Formula (4), we can get the result of the assignment.

The assignment is

$$
\begin{aligned}
& X_{1} \rightarrow \text { Resource } R_{2} \\
& X_{2} \rightarrow \text { Resource } R_{4} \\
& X_{3} \rightarrow \text { Resource } R_{1} \\
& X_{4} \rightarrow \text { Resource } R_{3}
\end{aligned}
$$

So, the solution of Formula (3) is

$$
11+9+4+5=29,
$$

and

$6+8+13+12=39$

is the result of Formula (2) either.

\section{Conclusions and future work}

In this paper, we present a novel economy model based on GRS, which is a new concept to organize and manage the grid resources in VO. Moreover, we optimize the allocation by combining the fuzzy theory with Hungarian algorithm. At the same time, we set up a procedure and algorithm in order to make more gross profits for the manager of GRS. There are some differences between our approach and the other ones which focus on grid resource consumers, not the manager. In terms of response time and wait time, the improvement of efficiency is achieved by our construction of GRS. The proposed method in this paper is an innovation of grid resource allocation from the angle of resource manager. However, the restrictive condition of the model and algorithm brings disadvantage of applications. Complication and efficiency is not evaluated enough while large numbers of resources and consumer exist. The examples are just a small scale situation (only $n=4$ ). It may be very difficult when the $\mathrm{n}$ is bigger. We plan to investigate approaches to solve it in our GRS-based posted price model as future work.
Acknowledgement This research was supported by Zhejiang Provincial Natural Science Foundation of China (Grant No. Y1090328), China Natural Science Foundation (NSF) (Grant No. 60803105, 60863016) and also supported by the MKE (The Ministry of Knowledge Economy), Korea, under the ITRC (Information Technology Research Center) support program supervised by the NIPA (National IT Industry Promotion Agency) (NIPA-2010-C1090-1031-0004).

Open Access This article is distributed under the terms of the Creative Commons Attribution License which permits any use, distribution, and reproduction in any medium, provided the original author(s) and the source are credited.

\section{References}

1. Buyya, R., Abramson, D., \& Venugopal, S. (2005). The grid economy, special issue on grid computing. Proceedings of the IEEE, 93(3), 698-714.

2. Buyya, R., Stockinger, H., Giddy, J., \& Abramson, D. (2001). Economic models for management of resources in peer-to-peer and grid computing, technical track on commercial applications for high-performance computing. In SPIE international symposium on the convergence of information technologies and communications (ITCom 2001), August 20-24, Denver, Colorado, USA (pp. 5-8).

3. Buyya, R., Abramson, D., Giddy, J., \& Stockinger, H. (2002). Economic models for resource management and scheduling in grid, concurrency and computation. Software, Practice \& Experience, 14(13-15), 1507-1542.

4. Foster, I., Kesselman, C., \& Tuecke, S. (2001). Anatomy of the grid: enabling scalable virtual organizations. Intl. J. Supercomputer Applications., 15(3), 200-222. www.globus.org/research/ papers/anatomy.pdf.

5. Backschat, M., Pfaffinger, A., \& Zenger, C. (1996). Economicbased dynamic load distribution in large workstation networks. In Lecture notes in computer science: Vol. 1124. Proceedings of the 2nd international Euro-Par conference (Euro-Par 1996), Lyon, France, August 1996 (pp. 631-634). Heidelberg: Springer.

6. Yemini, Y., Dailianas, A., Florissi, D., \& Huberman, G. (2000). MarketNet: protecting access to information systems through financial market controls. Decision Support Systems, 25(1-2), 205216

7. HP Grid computing. http://www.hp.com/techservers/grid (6 December 2004).

8. Stuer, G., Vanmechelen, K., \& Broeckhove, J. (2007). A commodity market algorithm for pricing substitutable grid resources. $\mathrm{Fu}$ ture Generations Computer Systems, 23(5), 688-701.

9. Eymann, T., Reinicke, M., Ardaiz, O., Artigas, P., Freitag, F., \& Navarro, L. (2003). Decentralized resource allocation in application layer networks. In Proceedings of the 3rd international symposium on cluster computing and the grid (CCGrid 2003), Tokyo, Japan, May 2003 (pp. 645-650). Los Alamitos: IEEE Comput. Soc.

10. Kale, L. V., Kumar, S., Potnuru, M., DeSouza, J., \& Bandhakavi, S. (2004). Faucets: efficient resource allocation on the computational grid. In Proceedings of the international conference on parallel processing (ICPP 2004), Montreal, Canada, August 2004 (pp. 396-405). Los Alamitos: IEEE Comput. Soc.

11. Lai, K., Huberman, B. A., \& Tycoon, F. L. (2004). A distributed market-based resource allocation system. Technical report cs.DC/0404013, HP Lab, Palo Alto, April.

12. Chun, B. N., \& Culler, D. E. (2000). Market-based proportional resource sharing for clusters. Technical report CSD-1092, Computer Science Division, University of California at Berkeley, January. 
13. Cooper, B. F., \& Garcia-Molina, H. (2002). Bidding for storage space in a peer-to-peer data preservation system. In Proceedings of the 22nd international conference on distributed computing systems (ICDCS 2002), Vienna, Austria, July 2002 (pp. 372-381). Los Alamitos: IEEE Comput. Soc.

14. Driskill, R., \& McCafferty, S. (2001). Monopoly and oligopoly provision of addictive. Goods International Economic Review, 42(1), 43-72.

15. Anastasiadi, A., Kapidakis, S., Nikolaou, C., \& Sairamesh, J. (1998). A computational economy for dynamic load balancing and data replication. In Proceedings of the 1st international conference on information and computation economies (ICE'98), Charleston, SC, October 1998 (pp. 166-180). New York: ACM Press.

16. Ferguson, D. F., Yemini, Y., \& Nikolaou, C. (1988). Microeconomic algorithms for load balancing in distributed computer systems. In Proceedings of the 8th international conference on distributed computing systems (ICDCS'88), San Jose, CA, June 1988 (pp. 491-499). Los Alamitos: IEEE Comput. Soc.

17. Yemini, Y., Dailianas, A., Florissi, D., \& Huberman, G. (2000). MarketNet: protecting access to information systems through financial market controls. Decision Support Systems, 25(1-2), 205216.

18. Ernemann, C., Hamscher, V., \& Yahyapour, R. (2002). Economic scheduling in grid computing. Lecture Notes in Computer Science, 2537, 128-152.

19. Yu, J., Li, M., Li, Y., Hong, F., \& Gao, M. (2004). A framework for price-based resource allocation on the grid PDCAT. In LNCS: Vol. 3320 (pp. 341-344).

20. Menasce, D. A., \& Casalicchio, E. (2004). A framework for resource allocation in grid computing in Modeling, analysis, and simulation of computer and telecom-munications systems (MASCOTS 2004). In Proceedings of the IEEE computer society's 12th annual international symposium (pp. 259-267).

21. Foster, I., \& Kesselman, C. (2004). The grid 2 blueprint for a new computing infrastructure. Amsterdam: Elsevier.

22. Xu, J., Hu, Z., \& Wang, W. (2004). Operations research. Science Press (pp. 211-217).

23. Song, Y., Chen, M., \& Zhang, S. (2001). An efficient algorithm for solving two multi-object generalized assignment problems and its application. Journal of Huazhong University of Science \& Technology, 29(1), 70-72.

24. Song, Y., Chen, M., \& Zheng, Z. (2000). Fuzzy Hungary algorithm for solving the multi-object generalized assignment problem. Journal of Naval University of Engineering, 5, 77-94.

25. Li, M., Chen, X., Jiao, F., \& Wu, Z. (2007). Optimization of grid resource allocation combining fuzzy theory with generalized assignment problem. In The 6th international conference on grid and cooperative computing (GCC2007), 2007 August

26. Li, M., Li, J., \& Xie, S. (2007). Posted price model based on GRS and its optimization using in grid resource allocation. In The 3th international conference on wireless communications, networking and mobile computing (WilCOM 2007), 2007 September

27. Li, M. (2007). Improvement of commodity and posted price model based on GRS. In The 2th international conference on computer science \& education (ICCSE2007), 2007 July

28. Lei, S., Zhang, Y., Yang, L. T., Wang, Y., Hauswirth, M., \& Xiong, N. (2010). TPGF: geographic routing in wireless multimedia sensor networks. Telecommunications Systems, 44(1-2), 79-95.

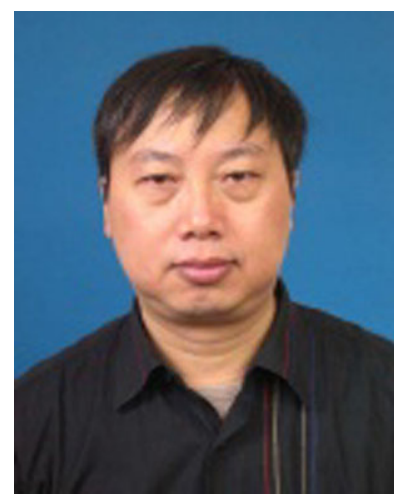

Mingbiao Li received his diploma degree from the Department of Mathematics, Jiang Xi University and his master degree from the Department of computer science, Wuhan University, China.

Now he is the Ph.D. candidate of computer college, Wuhan University. He has been a teacher of Gan Nan normal teachers college and Wenzhou University from 1983. His research interests are algorithm in distributed and paralleled computing, $\mathrm{P} 2 \mathrm{P}$, grid computing, and cloud computing. As a vice professor of computer science, Wenzhou University, he has finished about 10 projects, including Zhejiang NSF, Zhejiang Educational Committee, and published about 30 papers in the field of networks computing.

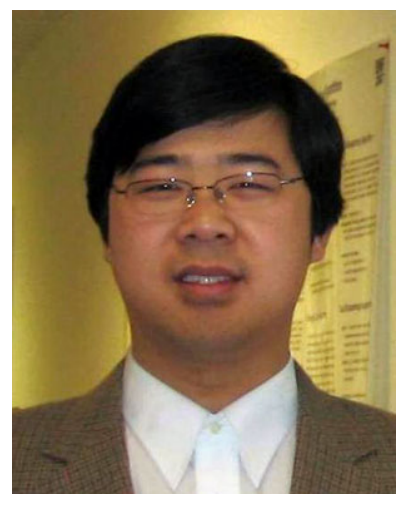

Naixue Xiong received his both $\mathrm{Ph} . \mathrm{D}$. degrees in Wuhan University (about software engineering), and Japan Advanced Institute of Science and Technology, respectively (about dependable networks). His research interests include Communication Protocols, Network Architecture and Design, and Optimization Theory. Until now, he published over 200 research articles/proceedings, including about 130 journal papers. Some of his works were published in IEEE JSAC, IEEE or ACM transactions, IEEE INFOCOM, and IPDPS. He has been a General Chair, Program Chair, Publicity Chair, PC member and OC member of over 100 international conferences, and as a reviewer of about 100 international journals, including IEEE JSAC, IEEE Transactions on Communications, IEEE Transactions on Mobile Computing, IEEE Trans. on Parallel and Distributed Systems. $\mathrm{He}$ is serving as an editor for over 10 international journals, and a guest editor for over 10 international journals, including WINET and MONET. He has received the Best Paper Award in the 10th IEEE International Conference on High Performance Computing and Communications (HPCC-08) and the Best student Paper Award in the 28th North American Fuzzy Information Processing Society Annual Conference (NAFIPS2009). He is a member of IEEE, TCPP, and IET. E-mail:nxiong@cs.gsu.edu.

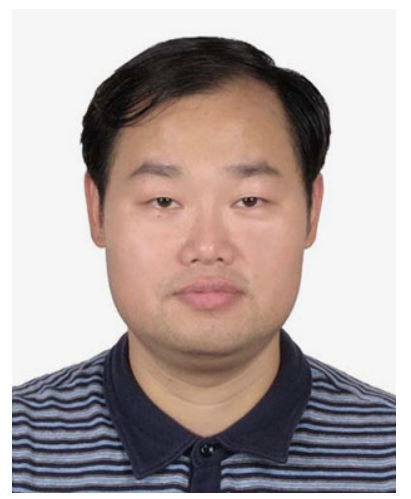

Bo Yang is a teacher and Ph.D. student at the Jiangxi University of Finance and Economy, China. $\mathrm{He}$ received his master degree in computer software from the University of Nanchang. He is currently a teacher of information technology school in Jiangxi University of Finance and Economy. Until now, he published more than 10 research articles. His current research focus is on security of interdomain routing in distributed networks and software engineering. Email: jxncyangbo2002@163.com. 


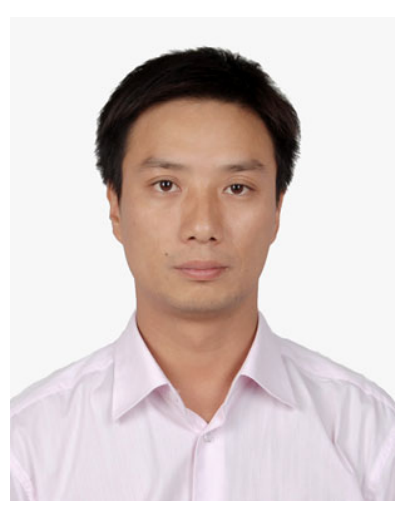

Zhonghua Li received his Ph.D. degree in School of Computer Science from Northwestern Polytechnical University. He is now an associate professor at School of Information Technology, Jiangxi University of Finance \& Economics.

His research interests include Information Security, Multimedia Reliable Transfer Service and E-Commerce Security. E-mail: chinalee@ jxufe.edu.cn

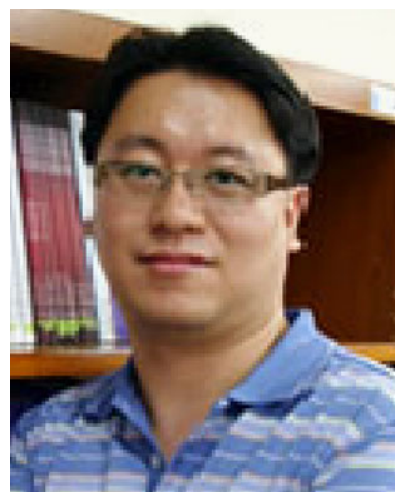

Jong Hyuk Park received his Ph.D. degree in Graduate School of Information Security from Korea University, Korea. He is now a professor at the Department of Computer Science and Engineering, Kyungnam University, Korea. Dr. Park has published many research papers in international journals and conferences. Dr. Park has been served as chairs, program committee or organizing committee chair for many international conferences and workshops. Dr. Park is the founder of International Conference on Multimedia and Ubiquitous Engineering (MUE), International Conference on Intelligent Pervasive Computing (IPC), and International Symposium on Smart Home (SH). Dr. Park is editor-in-chief of the International Journal of Multimedia and Ubiquitous Engineering (IJMUE), the managing editor of the International Journal of Smart Home (IJSH). In addition, he has been served as a Guest Editor for international journals by some publishers: Oxford, Emerald, Hindawi, Springer, Elsevier, Inderscience, SERSC. Dr. Park's research interests include Digital Forensics, Security, Ubiquitous and Pervasive Computing, Context Awareness, Multimedia Services, etc.

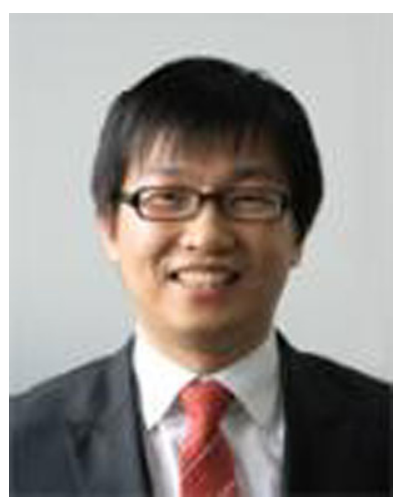

Changhoon Lee received his Ph.D. degree in Graduate School of Information Management and Security (GSIMS) from Korea University, Korea. He is now a professor in the School of Computer Engineering, Hanshin University, Korea.

$\mathrm{He}$ is currently an editorial board member of IJITCC and JIPS. He has been serving not only as a chair, a program committee, an organizing committee chair for many international conferences and workshops but also as a guest editor for international journals by some publishers.

His research interests include information security, cryptology, digital forensics, ubiquitous and pervasive computing etc. He is currently a member of the IEEE, IEEE CS, IEEE Communications, FTRA, IACR, KIISC, KIPS, KITCS, KMMS, and KONI societies. Email: cryptography1@gmail.com. 